\title{
O Papel do Desenvolvimento Econômico no Debate Teórico sobre Transições de Regimes Políticos'
}

Teresa Cristina Schneider Marques ${ }^{2}$

\section{Resumo}

Os estudos teóricos que procuraram compreender os fatores que influenciaram a manutenção das democracias sempre levaram em consideração o desenvolvimento econômico. Porém, diferentes papéis foram atribuídos a esta variável pelas diferentes orientações temáticas no estudo da democracia, dentre os quais destacamos o enfoque culturalista e o enfoque institucionalista por meio de duas obras consideradas clássicas: Comunidade e democracia: a experiência da Itália moderna, de Robert D. Putnam; e Democracy and development: Political Institucions e Material Well-Being in the World. 1950-1990 de Adam Przeworski, Miguel Alvarez, José Antônio Cheibub e Fernando Limongi. Esse ensaio busca analisar essas duas obras tendo como eixo a relação entre economia e transições de regimes políticos. Busca-se compreender qual o papel atribuído pelos institucionalistas e culturalistas para a variável econômica, bem como identificar as suas contribuições para a compreensão sobre as variáveis que possibilitem a emergência de regimes autoritários.

Palavras-chave: Desenvolvimento econômico. Transições políticas. Estudos teóricos.

\section{Introdução}

Mudanças de regimes políticos são eventos raros, mas tais processos ainda ocorrem, incentivando os estudos que buscam identificar padróes nos processos de transição política. A relação entre transformaçōes de regimes políticos e economia é presença certa enquanto variável na maior

I Uma primeira versão deste ensaio foi apresentada e publicada nos anais do sexto encontro da Associação Latino-Americana de Ciência Política (ALACIP), em 2012. Agradeço aos pareceristas anônimos da revista Política e Sociedade pelas críticas construtivas que permitiram que o ensaio apresentasse um debate mais atualizado.

2 Doutora em Ciência Política pela Universidade Federal do Rio Grande do Sul (UFRGS). Professora adjunta do programa de pós-graduação em Ciências Sociais da Pontificia Universidade Católica do Rio Grande do Sul (PUCRS).Endereço eletrônico: teresa.marques@pucrs.br 
parte desses estudos. O contexto atual incentiva ainda mais este debate, pois os governos dos países latino-americanos que passaram por processos de redemocratização no início da década de 1980 se vêem diante de graves crises econômicas que não raro são usadas como justificativas para reformas políticas que afetam sobremaneira o funcionamento das instituiçóes. Logo, é neste contexto que está inserida a contribuição que o presente ensaio pretende apresentar.

A economia sempre esteve automaticamente relacionada com a estabilidade de regimes políticos. Na ciência política é sempre presente e a ideia de que o desenvolvimento econômico influencia na manutenção de democracias, e que a ausência desse, pode facilitar a emergência de regimes autoritários. Também convém destacar que diferentes papéis foram atribuídos a esta variável por cada um dos principais enfoques e orientaçóes temáticas no estudo de transiçóes. Ora como coadjuvante, ora como ator principal, o fato é que o desenvolvimento econômico quase sempre é apontado como uma das causas da estabilidade de regimes políticos. Contudo, por algum tempo estiveram presentes as perguntas: Por que influencia? Como influencia?

Dentre as orientaçóes teóricas que marcaram os estudos sobre transiçôes de regimes políticos, acreditamos que receberam maior destaque duas teses orientadas pela análise de macro-variáveis que levaram em consideração o aspecto econômico. A primeira delas é a defendida por Robert D. Putnam, que na obra Comunidade e democracia: a experiência da Itália moderna (1996) se baseia em macro-variáveis de ordem cultural para explicar as mudanças de regime. Para os autores, o desenvolvimento econômico possibilitaria o surgimento do capital social, que seria a condição indispensável para a manutenção de regimes democráticos, consequentemente, a ausência deste possibilitaria a emergência de ditaduras. A segunda delas é a tese defendida por autores tais como Adam Przeworski, Miguel Alvarez, José Antônio Cheibub e Fernando Limongi na obra já considerada clássica Democracy and development: Political Institucions e Material Well-Being in the World. 1950-1990 (2000). Nessa obra, os autores se basearam em análises comparativas para apontar o desenvolvimento econômico como a pré-condição essencial para a manutenção de democracias. 
Esse artigo busca analisar estes dois enfoques, buscando compreender qual o papel atribuído por ambos para a variável econômica, bem como identificar as suas contribuiçóes para a compreensão sobre as variáveis dependentes e independentes que causam a emergência de regimes autoritários. Assim, procede-se a uma análise das duas orientaçóes temáticas focando sobretudo na análise dessas duas obras selecionadas, objetivando compreender o conceito de capital social e a explicação exógena apresentada pela análise econômica. Posteriormente, serão brevemente discutidas as críticas para as duas teses e as novas possibilidades teórico-metodológicas apresentadas pela Ciência Política, sobretudo as abordagens que se enquadram nas chamadas "explicações políticas das transiçôes". Maior destaque é conferido à teoria neo-institucional, apresentada por autores como Douglass North, que apontam as instituiçóes como a base para o surgimento e estabilidade de regimes democráticos e à chamada abordagem "elitista".

\section{O enfoque culturalista em Comunidade e democracia}

A teoria dos jogos prevê que o comportamento não cooperativo é uma ação frequente, e a falta de informação seria apontada pelos estudiosos que compartilham desta teoria como a principal causa para a ausência de cooperação. O dilema do prisioneiro ilustra de forma clara este problema de interação social: dois indivíduos cúmplices, ao serem presos e alocados em diferentes celas - consequentemente, sem a possibilidade de manterem algum tipo de comunicação -, são persuadidos a delatar o cúmplice primeiro, com a promessa de obter a liberdade. Diante da falta de informação sobre a ação do outro, ambos confessam o crime ao mesmo tempo em que delatam a participação do cúmplice. Dessa forma, fornecem subsídios concretos para que ambos sejam condenados, o que não ocorreria caso tivessem optado por não fazer a denúncia, independente da ação do cúmplice (PUTNAM, 2006, p. 174).

Para Douglass C. North, a conduta cooperativa que traria uma solução para o "dilema do prisioneiro" apenas pode ocorrer quando os indivíduos atuam repetidamente, quando tem suficiente informação sobre o outro e quando o grupo é composto por poucos participantes (NORTH, 1993, p. 24). Putnam, por sua vez, após realizar um estudo sobre a experiência da 
Itália moderna - abordando um período que compreende mais de 20 anos, mais especificamente, desde 1970 até meados dos anos $90-$, que resultou na obra Comunidade democracia: a experiência da Itália Moderna (2006), defende uma diferente solução para este tipo de dilema previsto pela teoria dos jogos, baseado no estudo da cultura política e do capital social. A confiança interpessoal é a principal variável destes estudos, e a hipótese central seria a de que o crescimento da confiança torna a sociedade mais associativa, o cidadão se envolve mais politicamente, dessa forma, tornando a democracia mais estável (RENNÓ, 2001, p.34). Nas palavras de Putnam:

A cooperação voluntária é mais fácil numa comunidade que tenha herdado um bom estoque de capital social sob a forma de regras de reciprocidade e sistemas de participação cívica. Aqui o capital social diz respeito a características da organização social como confiança e normas e sistemas que contribuam para aumentar a eficiência da sociedade, facilitando as ações coordenadas (PUTNAM, 2006, p. 177).

Portanto, a base do sucesso democrático seria a confiança, a solidariedade e a tolerância, entendidos enquanto atributos do comportamento cívico. A existência destes atributos tornaria possível a comunidade cívica, marcada pela participação nos assuntos públicos, e pela igualdade de direitos e deveres entre os cidadáos. Vale destacar que a noçáo de cultura cívica ganhou destaque a partir dos anos 1960, com os trabalhos de Almond e Verba (SANTOS, 2004, p. 147), que apontavam uma relação direta e positiva entre valores políticos de massa e estabilidade democrática.

Entretanto, os defensores do capital social como fator indispensável para o fortalecimento da comunidade cívica - e consequentemente, para a estabilidade de democracias -, apontam que o processo de construção desse capital poderia ser prejudicado pelo "familismo amoral", que se basearia na idéia de que:

Os indivíduos agem orientados pelo desejo de obter o máximo de vantagens para a sua família nuclear e pelo pressuposto de que os outros irão agir da mesma forma. O resultado geral é uma situação em que as pessoas só interagem na esfera privada, abandonando a esfera pública. [...] O familiarismo moral baseia-se na preponderância de comportamentos oportunistas orientados para maximizar o ganho privado. Uma vez que os indivíduos agem guiados apenas por seus objetivos imediatos, o alcance das estratégias disponíveis é amplo, incluindo atitudes não necessariamente orientadas por restrições legais ou morais (RENNÓ, 200I, p.35). 
Todavia, segundo Putnam, comportamentos individualistas tais como o "familismo amoral", poderiam ser superados a partir da implementação de determinados mecanismos, que poderiam fortalecer ou até mesmo criar o estoque do capital social nas sociedades. Entre os mesmos, merecem destaque as cooperativas de crédito rotativo, que teriam uma atuação que iria além do âmbito econômico, ao proporcionar o fortalecimento da solidariedade comunitária. Tal fortalecimento se tornaria possível ao adotar o capital social como uma espécie de garantia, diante da ausência de um capital convencional, com o objetivo de ampliar os serviços de crédito disponíveis nestas comunidades, e consequentemente, a expectativa de ganhos (PUTNAM, 2006, p. 178-179).

Regras de reciprocidade e sistemas de participação cívica também constituem formas de se criar a confiança pessoal para Putnam. Tais regras seriam impostas e mantidas através de sançóes e educaçáo cívica, e, entre as mesmas, mereceria relativo destaque a reciprocidade, pois esta diminuiria os custos da transação e facilitaria a cooperação (PUTNAM, 2006, p. 181).

A partir do momento no qual o capital social se tornasse presente na sociedade, o mesmo tenderia a crescer na medida em que a sua utilização fosse ampliada. Em outras palavras, pode-se afirmar os estoques de capital social, tais como a confiança, normas e sistemas de participação são cumulativos e se reforçam mutuamente (PUTNAM, 2006, p. 179). Por outro lado, o seu desuso reforça a desconfiança e proporciona a diminuição do capital social.

Diante da ausência da cooperação, a coerção de um terceiro pode ser vista por estas sociedades como uma forma de manutenção do contrato social. Este "terceiro" pode ser o clientelismo, a coerção ilegal ou o governo autoritário. Logo, para Putnam a emergência de regimes autoritários seria uma solução equivocada e imediatista para a ausência de cooperação nas sociedades. Inglehart compartilha da mesma tese de Putnam, defendendo que sociedades que são deficientes em confiança interpessoal tendem a ser favoráveis a regimes autoritários. Também para este autor, a estabilidade democrática dependeria do enraizamento de valores políticos e de confiança interpessoal (INGLEHART apud SANTOS, 2004, p. 147), já que considera que a cultura é anterior ao regime político. 
Baseado neste pressuposto que compartilha com Putnam, Inglehart procura acrescentar à análise referentes empíricos dos componentes da cultura cívica em nível individual. Assim, segundo Rennó, reforça a hipótese de que:

A estabilidade de um regime é altamente influenciada pelas orientações culturais dos seus cidadãos. Um padrão de comportamento coerente, constituído de satisfação de vida e política, confiança interpessoal e apoio à ordem social existente, é essencial para o sucesso de um regime democrático (RENNÓ, 200I, p. 37).

É importante destacar que, tanto para Putnam quanto para Inglehart, o desenvolvimento econômico teria a função de fortalecer o capital social: "Segundo Inglehart, ao desenvolvimento econômico geralmente se seguiria declinio dos valores religiosos, do provincianismo e das identidades culturais tradicionais" (SANTOS, 2004, p. 147). Considera ainda que a democracia efetiva obtida com a cultura política de tolerância, participação e confiança poderia ser mantida enquanto os níveis de desenvolvimento econômico forem satisfatórios e com a experiência com as instituiçóes democráticas (INGLEHART; WELZEL, 2003, p.19).

Portanto, o desenvolvimento econômico não interferiria diretamente na estabilidade de regimes democráticos, mas sim, indiretamente, pois a sua incidência possibilitaria a melhora no sistema educacional, trazendo como consequência o enraizamento de valores democráticos e da confiança interpessoal. Putnam, por sua vez, defende ainda que o desenvolvimento econômico, por acentuar as vantagens do oportunismo, da trapaça e da transgressão, torna o capital social ainda mais indispensável para a manutenção da ordem social (PUTNAM, 2006, p. 187). Dessa forma, percebe-se que os estudos que se baseiam na ideia de comunidade cívica e capital social, atribuem a esta variável econômica uma posição secundária na determinação de regimes políticos.

Contudo, também receberam grande destaque os estudos que apontavam a variável econômica como a condição central para a manutenção de regimes democráticos. Entre os mesmos, merecem destaque os realizados por Przeworski, Alvarez, Cheibub e Limongi, analisados nos tópico seguinte. 


\section{As contribuições de Democracy and development}

Adam Przeworski, Michael Alvarez, José Antônio Cheibub e Fernando Limongi utilizaram a metodologia comparativa para verificar padrôes nos processos de transiçóes políticas em um estudo que resultou na comentada obra Democracy and development (2000). Como a democracia está geralmente relacionada com o nível de desenvolvimento econômico, o principal objetivo destes autores neste estudo era compreender se as democracias são mais propensas a emergir em países ditatoriais desenvolvidos economicamente, ou, tendo emergido por outras razóes além do desenvolvimento econômico, se são mais propensas a sobreviver em países que já são desenvolvidos economicamente. Diferentes variáveis foram utilizadas pelos autores nesta análise, e dentre estas, merecem destaque: o nível de desenvolvimento econômico (medido através da renda per capita); as políticas legais do país; a sua história política, a sua estrutura religiosa; a sua divisão ethnológica e ethnolinguística e o meio internacional (PRZEWORSKI et al., 2000, p. 79).

Com efeito, após realizar a análise comparada, em 749 dos casos o regime esperado não era o que podia ser observado. Em muitos casos a democracia foi um legado colonial, que acabou sendo abandonada para se desviar sozinha contra todas as desproporçóes. Em outros casos, ela foi imposta pelos Aliados após o término da Segunda Guerra Mundial. Muitos países passam por democracias que náo deveriam ter acontecido, caso observadas as suas condiçôes, assim como existem países - principalmente latino americanos - que vivenciaram democracias sob condiçóes adversas para esta. Muitos países esperaram muito mais do que as condiçóes previam para fazer a transição para a democracia, enquanto outros, se tornaram regimes autoritários, mesmo com fatores que indicavam que eles deveriam ter regimes democráticos (PRZEWORSKI et al., 2000, p. 83-87).

Diante destas irregularidades nos padrôes observados, os autores chegaram à conclusão de que o desenvolvimento econômico é a melhor maneira para prever os regimes políticos, mas ainda assim, não é determinante. Baseados nesta conclusão, desenvolveram uma nova explicação para a incidência da democracia a partir do nível de desenvolvimento, que se opóe à explicação endógena, que seria a teoria da modernização. De acordo com 
a teoria da modernização, as democracias estão mais sujeitas a emergir como resultado do desenvolvimento econômico. A modernização possibilitaria a acumulação de mudanças sociais que tornariam uma sociedade pronta para o processo final, que seria a democracia. A hipótese central é que países autoritários, na medida em que se tornassem desenvolvidos economicamente, passariam a ser democracias (PRZEWORSKI et al, 2000, p. 88).

A nova explicação fornecida por Przeworski e os demais autores argumenta que a democracia surge de maneira exógena, por diferentes razóes, e não como um resultado do desenvolvimento econômico. Para estes autores, os casos do Brasil, Portugal, Tchecoslováquia e até mesmo da Coreia do Sul e da Grécia, utilizados pelos teóricos da modernização como casos exemplares de que o desenvolvimento econômico adquirido pelos países durante as ditaduras permitiu a emergência de democracias, são casos isolados e raros (PRZEWORSKI ET AL, 2000, p. 96-97).

Portanto, defendem que o poder do desenvolvimento econômico em derrubar ditaduras é insignificante. O nível de desenvolvimento econômico, pelo menos quando medido pelo índice de renda per capita, dá poucas informaçóes sobre as chances de transição para a democracia. Não há dúvida de que as democracias são mais facilmente observadas em países com altos índices de desenvolvimento. Entretanto, para os autores, isso náo quer dizer que as democracias são mais sujeitas a emergir em países autoritários que se desenvolveram economicamente, mas sim que, tendo emergido, elas tem mais chances de sobreviver em países que já são desenvolvidos economicamente.

A análise comparada realizada neste estudo apresenta ainda um resultado que se opóe à ideia de que o alto nível de desenvolvimento econômico possibilita uma melhora na educação do país, e que isso, por sua vez, incentivaria as pessoas a se ligarem a valores democráticos. Para Putnam, isso aumentaria a probabilidade de uma democracia sobreviver. Tal oposição se baseia em casos como o do Uruguai, que tinha um alto índice educacional entre os seus habitantes quando o seu sistema democrático caiu em 1973 (PRZEWORSKI ET AL, 2000, p. 101). Logo, por razóes que os autores consideram que não conseguiram identificar, o desenvolvimento torna as democracias mais estáveis, independente da educação ou de valores democráticos. 
Portanto, entre todas as variáveis analisadas no referido estudo, o nível de desenvolvimento econômico foi o que demonstrou ser mais essencial para a estabilidade de democracias, muito embora os autores afirmem que não conseguiram explicar de que forma isso ocorre. A frequente troca de lideranças no governo também pode afetar o regime, bem como um passado de regimes instáveis, as instituiçóes e a heterogeneidade linguística e religiosa. Por outro lado, legados coloniais e cultura (indicada pela religiáo predominante neste estudo), pouco afeta.

\section{Além das duas perspectivas em debate}

Diante destas duas abordagens, é válida a pergunta: $\mathrm{O}$ desenvolvimento econômico é o que de fato importa? Ou ele importa apenas indiretamente porque propicia o surgimento de valores cívicos? Ou ainda, em outras palavras: o desenvolvimento econômico desempenharia papel protagonista ou coadjuvante na manutenção de regimes democráticos? A resposta a estas perguntas permitiria compreender se é a cultura cívica ou o desenvolvimento econômico o que vem antes.

As duas obras analisadas até o momento neste ensaio atribuem um papel importante para o desenvolvimento econômico, porém, apontam diferentes motivos para explicar a sua importância na manutenção de regimes políticos. Para a vertente culturalista, o desenvolvimento econômico, ao promover uma melhora no nível educacional dos seus habitantes, possibilitaria um incremento de valores democráticos e da confiança interpessoal na sociedade. Dessa forma, promoveria o surgimento do capital social, que seria a condição indispensável para a manutenção de democracias. Para os estudiosos da vertente econômica, o desenvolvimento em si seria o fator indispensável para a estabilidade do regime, pois com ele, os custos da implantação de um regime autoritário se tornariam mais relevantes. Diante disso, tanto os ricos, quanto os pobres tendem a preferir a democracia.

Apesar das diferenças, segundo Tribbes, as duas obras se encaixam em uma mesma categoria de estudos acerca dos processos de transição: as explicaçóes sociais, que por sua vez, se subdividem nas duas explicaçôes destacadas neste artigo: a explicação que parte da análise de variáveis econômicas e as explicaçôes de cultura política e mobilização social (TRIBESS, 2012). 
Porém, a complexidade dos processos de transição na América do Sul, incentivaram estudos que procuraram ir além da análise das variáveis econômicas e sociais para compreender as mudanças de regimes políticos (MARQUES, 2010). Assim, observou-se surgimento e avanço de uma outra categoria de estudos sobre os processos de transição, chamada por Tribess de "explicações políticas das transiçôes":

As explicações que se tornaram clássicas na Ciência Política para astransições de Brasil e Argentina são as que priorizam as variáveis políticas, especialmente a atuação das elites e os arranjos institucionais (TRIBESS, 2012, p. 19).

Dessa forma, a chamada categoria "explicações políticas das transiçóes”, por sua vez, se subdivide em dois subgrupos: as explicaçóes que se baseiam na análise do funcionamento das instituiçôes - também chamada "institucional" - e as explicaçôes se baseiam na análise das relaçôes intraelites - também chamadas "elitistas" (TRIBESS, 2012). Enquanto a explicação institucional se baseia na análise das formas utilizadas pelos militares no uso político dos mecanismos institucionais, a explicação elitista enfocou as açóes e escolhas das elites políticas ao longo do processo de transição.

A abordagem institucional defende que a evolução política, econômica e social de uma sociedade é condicionada pela evolução das suas instituiçóes. Os regimes políticos, portanto, dependeriam, sobretudo, do desempenho institucional, que seria o responsável pela criação das condiçóes necessárias para a emergência e manutenção da democracia.

Um dos principais questionamentos colocados pelos institucionalistas diz respeito à hipótese de que o capital social seja uma pré-condição para o surgimento e manutenção de regimes democráticos. Dentre as críticas dos institucionalistas ao enfoque culturalista de Putnam e Inglehart, Rennó destacou os apresentados por Muller e Seligson. Nos seus estudos os autores argumentam que a noção de capital social inverte a relação causal entre cultura e democracia. Para eles, a cultura cívica não interfere de maneira alguma na estabilidade de democracias, pois a mesma seria um resultado da estabilidade democrática, e não o contrário:

A persistência da democracia no tempo provoca um aumento do nível de atitudes de cultura cívica porque altos níveis de consciência política subjetiva, orgulho pelo sistema político e 
confiança interpessoal são uma resposta racional, culta à experiência de viver em um país que tem um regime democrático estável. Uma vez que a democracia estimula os grupos de ação coletiva pacífica, ela reforça a difusão do comportamento confiante (RENNÓ, 200 I, p. 37).

Assim, para os estudiosos desta corrente, as instituiçóes náo apenas agregam valores, como também possuem a capacidade de "converter preferências em ações não necessariamente correspondentes às pretensões originais" (SANTOS, 2004, p.150). Isso se daria através da própria ação das instituiçóes, que segundo esses teóricos, apenas podem ser consideradas eficientes quando oferecem soluçóes aos problemas de açáo coletiva, ou em outras palavras, quando conseguem eliminar os comportamentos que diferem do seu padrão seletivo. Por isso, para os institucionalistas:

Se o lapso que separa a escolha de cursos de ação alternativos de comportamentos cooperativos pode ser representado pela confiança na reciprocidade do comportamento dos demais, parece incoveniente supor que a geração espontânea dessa confiança social não só venha antes (e independa) de um quadro institucional propício (por mais rudimentar que este seja) como seja condição para seu surgimento (SANTOS, 2004, p. 15I).

Essa capacidade das instituiçóes em gerar valores se torna possível com as regulamentaçóes, regras, leis e tarifas. Para a teoria institucional, as regras não serão seguidas de maneira espontânea, ao menos que o custo para a ignorância das mesmas seja tấo elevado que o seu cumprimento se torne mais vantajoso (SANTOS, 2004, p.152). Portanto, é através destes procedimentos que obrigam todos a seguirem um determinado padrão de comportamento social, que as instituiçôes conseguem garantir o contrato social.

Também é através destes procedimentos que a teoria institucional explica o papel do desempenho econômico na manutenção de regimes políticos. Dentre os autores que atribuem um papel fundamental às instituiçóes na economia, merece destaque Douglass North, ganhador do prêmio Nobel em conjunto com Robert Fogel em 1993. Para North, as instituiçóes sáo a chave para o desenvolvimento econômico, pois as mesmas contam com a possibilidade de criar uma base de regras, leis e costumes que incentivam o incremento de atividades economicamente produtivas e possibilitam o acesso ao conhecimento e às novas tecnologias (NORTH, 1993, p. 135). A definiçãao sobre as instituiçôes apresentada por esse autor, evidencia esse papel de destaque atribuído a elas: 
As instituições são as regras do jogo em uma sociedade ou, mais formalmente, são as limitações idealizadas pelo homem que dão forma à interação humana. Por consequência, estruturam incentivos no intercâmbio humano, seja político, social ou econômico. O arranjo institucional condiciona o modo como as sociedades evoluem no decorrer do tempo, e por isso é a chave para compreender a evolução histórica3 (NORTH, 1993, p.13).

Assim, percebe-se que a teoria institucional estabeleceu um papel decisivo para as instituiçôes democráticas na explicação da manutenção de regimes políticos. Para os institucionalistas, as instituiçôes determinam náo apenas os valores de uma sociedade, mas inclusive o seu desempenho econômico. A interação entre todos esses fatores - culturais, políticos e econômicos - seria essencial para a manutenção de regimes democráticos. Contudo, seria apenas através da eficiência dos procedimentos estabelecidos pelas instituiçóes que todos esses fatores que garantem a democracia teriam a possibilidade de emergir.

Por sua vez, a abordagem elitista enfoca as negociaçóes entre os atores, as decisôes individuais ou de grupos que ocupam uma posição privilegiada no sistema (TRIBESS, 2012, p.19). Essa linha, segundo Adriano Codato, inaugurou a chamada "transitologia" que pode ser caracterizada da seguinte maneira:

Essa nova geração de trabalhos, que poderia ser agrupada sob otítulo pouco eufônico, mas bem preciso, de "transitologia" possui três características que a distinguem das análises macro-orientadas: (i) ênfase no estudo dos atores políticos - seus interesses, valores, estratégias etc. (em sintonia com a teoria da escolha racional e o individualismo metodológico; em oposição, portanto, a explicações classistas); (ii) destaque para os fatores endógenos de cada país no estudo do curso do processo de transição (e não a fatores globais do tipo "transformações no processo de acumulação capitalista"); e (iii) adoção de um conceito minimalista e pouco exigente de "democracia" (à la Schumpeter: a democracia é um método de seleção de lideranças), única forma, imaginou-se, de dar conta de uma série de casos bastante diferentes entre si (CODATO, 2005 p. 85).

Dessa forma, essa abordagem prioriza as chamadas micro-variáveis para compreender as transiçóes de regime e, assim, destacou o caráter incerto dos rumos assumidos pelos processos de transição. A obra organizada por O’Donnell e Schmitter (1986) ganha destaque entre os estudos que se

3 Tradução do original sob responsabilidade da autora. 
encaixam nessa categoria de abordagens políticas dos processos de transição, bem como contribuições de Karl e Schmitter (1991 Apud TRIBESS, 2012, p. 21).

Essa abordagem inverte o papel do desenvolvimento econômico nas explicaçôes sobre o surgimento de regimes democráticos. Segundo Tribess, autores dessa linha como Karl e Schmitter (1991) argumentam que

Fatores como crescimento econômico, distribuição equitativa de renda, alfabetização e educação, desenvolvimento e acesso aos meios de comunicação são analisados por esta corrente explicativa como "produtos de processos democráticos estáveis" (...) e não mais como requisitos prévios para a existência da democracia (TRIBESS, 20I2, p. 21).

A América do Sul foi o principal "laboratório" dessa abordagem, sobretudo os casos do Brasil e da Argentina. Tais estudos identificaram o caráter altamente negociado dos processos de transição na região, sobretudo no Brasil, considerado um caso de transição exemplar, segundo tais estudos. Dessa forma, a chamada "transitologia" veio a somar com os estudos que procuraram compreendem como surgem as democracias.

\section{Considerações finais}

Nos estudos que tem como objetivo a identificação dos fatores que interferem na escolha dos regimes políticos, diversas foram as variáveis empregadas. Nas obras analisadas neste ensaio, entendidas como "explicaçóes sociais" das transiçóes, podemos verificar que foram dadas preferências às macro-variáveis de ordem econômica (grau de desenvolvimento econômico) ou culturais (cultura cívica) como pré-condiçóes para a existência de democracias. Nas duas obras destacadas podemos perceber a presença do desenvolvimento econômico enquanto uma das variáveis observadas no estudo comparativo. Contudo, a importância atribuída ao aspecto econômico variou muito entre um enfoque e outro.

Para o enfoque culturalista, o desenvolvimento econômico teria o papel de possibilitar a emergência da tolerância, da cooperação pessoal e de outros componentes que são a base do capital social através da educação cívica. Para os teóricos desta corrente - com especial destaque para Putnam e Inglehart -, o capital social seria a variável independente, sem a qual, 
a democracia não seria possível. Dessa forma, consideram as instituições democráticas como uma variável dependente, pois a criação e o sucesso das mesmas dependeria da existência do capital social.

Por outro lado, alguns estudiosos procuraram verificar em estudos comparativos se o desenvolvimento econômico desempenharia um papel decisivo na escolha de regimes políticos. Entre os mesmos, mereceram relativo destaque os estudos realizados por Przeworski, Alvarez, Cheibub e Limongi. Estes autores chegaram à conclusão de que o desenvolvimento econômico de fato importa para a manutenção de democracias, mas não possuiu um poder significativo para derrubar regimes autoritários, ao contrário do que defendia a teoria da modernização.

Portanto, podemos perceber que o desenvolvimento econômico de fato importa. Seja contribuindo para a elevação do nível educacional dos seus habitantes, seja através da equalização de condiçóes, pode-se concluir que a sua existência é indispensável para a manutenção de regimes democráticos. Diante do debate teórico existente na ciência política sobre transiçôes e manutençôes de regimes políticos, aqui brevemente apresentado, pode-se argumentar que há um ponto de diálogo entre os culturalistas e institucionalistas ao atribuir ao desenvolvimento econômico um papel importante para a compreensão de regimes democráticos.

Entretanto, os casos da América do Sul apontam a limitação das chamadas abordagens sociais. As críticas feitas a essa abordagem, ao focarem em variáveis políticas, indicaram outros caminhos explicativos para a questão, com destaque para a análise das instituiçóes e das relaçóes intra-elites. Para além ainda desses caminhos, convém destacar as abordagens medianas - que combinam a análise de macro e micro-variáveis - para a compreensão de casos de transiçáo negociada, tais como brasileiro (ARTURI, 2001).

Portanto, o aspecto econômico com certeza é uma variável que importa para a compreensão dos processos de transição, muito embora não seja possível afirmar que o seu papel seja preponderante ao desempenhado pelas outras variáveis explicativas destacadas pelos estudos aqui apresentados. De qualquer forma, tal conclusão deixa claro que para evitar a emergência de regimes autoritários, é necessário que ocorra o constante incremento das atividades economicamente produtivas, bem como uma melhor distribuição de renda. 


\section{Referências}

ARTURI, Carlos. O Debate Teórico sobre Mudança de Regime Político: o Caso Brasileiro. Revista de Sociologia e Política, Curitiba, n. 17, 2001.

CODATO, Adriano. Uma história política da transição brasileira: da ditadura militar à democracia. Revista de Sociologia e Política, Curitiba, n. 25, 2005.

GUGLIANO, Alfredo Alejandro ; GALLO, Carlos Artur. On the ruins of the democratic transition: human rights as an agenda item in abeyance for the Brazilian democracy. Bulletin of Latin American Research, v. 32, p. 325-338, 2013.

INGLEHART, Ronald and WELZEL, Christian. Political culture and democracy: analysing crosslevel linkages. Comparative Politics, 36/1, 2003.

INGLEHART, Ronald. Cultura e democracia. In: HARRISON, L.; HUNTINGTON, S. A cultura importa: os valores que definem o progresso humano. Rio de Janeiro: Record, 2002.

KARL, Terry L. e SCHMITTER, Philippe C. Modos de transición en AméricaLatina, Europa del Sur y Europa del Este. In: La hora de la democracia. n. 128, 1991.

MARQUES, Teresa C. S. Transiçôes políticas na América Latina emperspectiva comparada. Pensamento Plural. Pelotas, n. 6, 2010.

O'DONNELL, Guillermo; SCHMITTER Philippe. Transitions from Authoritarian Rule: Tentative Conclusions about Uncertain Democracies. Baltimore: John Hopkins University Press, 1986.

NORTH, Douglass C. Instituciones, cambio institucional y desempeno económico. México: Fondo de Cultura Económica, 1993.

PRZEWORSKI, Adam; ALVAREZ, Miguel; CHEIBUB, José Antônio and LIMONGI, Fernando. Democracy and development: Political Institucions e Material Well-Being in the World. 19501990. Cambridge: Cambridge University Press, 2000.

PUTNAM, Robert. Comunidade e democracia: a experiência da Itália moderna. Rio de Janeiro: Fundação Getúlio Vargas, 1996.

RENNÓ, Lúcio R. Confiança interpessoal e comportamento político: microfundamentos da teoria do capital social na América Latina. In: Opiniáo pública, Campinas, v. VII, n. 1, 2001, p. 33- 59.

SANTOS, André Marenco dos. Democracia e valores cívicos: uma relação necessária? In: Novos Estudos CEBRAP, n. 69, p. 145-160, julho 2004. 
TRIBESS, Camila. Consideraçóes teóricas sobre as transiçóes políticas no Brasil e na Argentina. Dissertação de mestrado. Programa de pós-graduação em Ciência Política, Universidade Federal do Paraná (UFPR). Curitiba, 2012.

\section{The Role of Economic Development in the Theoretical Debate About Transitions of Political Regimes}

\section{Abstract}

The theoretical studies that tried to understand the factors that influenced the maintenance of the democracies always took into consideration the economic development. However, different roles were attributed to this variable by the different thematic orientations in the study of democracy, among which we highlight the culturalist approach and the institutionalist approach through two works considered classics: Community and democracy: the experience of modern Italy by Robert D Putnam; and Democracy and Development: Political Institutions and Well-Being Material in the World. 1950- 1990 by Adam Przeworski, Miguel Alvarez, José Antônio Cheibub and Fernando Limongi. This essay seeks to analyze these two works based on the relationship between the economy and the transitions of political regimes. It seeks to understand the role assigned by institutionalists and culturalists to the economic variable, as well as to identify their contributions to the understanding of the variables that allow the emergence of authoritarian regimes.

Keywords: economic development, political transitions, theoretical studies.

Recebido em 13/08/2017

Aprovado em: 03/10/2017 